\title{
Rolling contact fatigue in martensitic 100Cr6: subsurface hardening and crack formation
}

\author{
Jee-Hyun Kanga ${ }^{\mathrm{a}}$, R. H. Vegter ${ }^{\mathrm{b}}$, Pedro E. J. Rivera-Díaz-del-Castillo, ${ }^{\mathrm{a}, *}$ \\ ${ }^{a}$ SKF University Technology Centre, Department of Materials Science and Metallurgy, \\ University of Cambridge, 27 Charles Babbage Road, Cambridge, CB3 OFS \\ ${ }^{b}$ Department of Lubrication and Metallic Materials, \\ SKF Engineering and Research Centre, Kelvinbaan 16, 3439 MT Nieuwegein, \\ The Netherlands.
}

\begin{abstract}
Rolling contact fatigue tests on $100 \mathrm{Cr} 6$ steel were carried out with a ballon-rod tester. Microstructural damage was manifested by gradual hardness changes under the subsurface, and microcracks formed adjacent to inclusions; both being evidence of plastic deformation. The hardness increase appears to be due to the development of residual stress, while the microcracks form as a result of the concentration of stress around inclusions. The microcrack orientation is suggested to be affected by the stress state, depending on the degree of residual stresses generated. The residual stress development may be a key factor for optimising the bearing element testing methods, by considering its influence on the damage morphology.
\end{abstract}

Keywords: fatigue, hardening, martensite, steel, hardness measurement, light microscopy

\footnotetext{
${ }^{*}$ Corresponding author

Email address: pejr2@cam.ac.uk (Pedro E. J. Rivera-Díaz-del-Castillo)
} 


\section{Introduction}

During bearing operation, the material experiences rolling contact fatigue (RCF), where plastic deformation is manifested by special forms of microstructural damage such as dark-etching regions (DERs) and white-etching areas (WEAs, sometimes referred to as butterflies) due to repetitive rolling contacts between the components [1].

The best way to study the RCF damage is via full-scale bearing endurance testing, where the actual operation environment can be reproduced [2]. However, the full-scale tests are not economical in time and cost due to the competent endurance of the tested bearings. As a result, bearing element testing has been introduced, employing samples with a relatively simple shape such as cylinders and spheres. They have been found to be successful in reproducing the life ranking from the full-scale test, enabling the initial screening of new materials and operation conditions [3-5].

However, the performance results due to element testing may be misleading due to a different stress state being present in actual applications [2]. This can be verified by examining the morphology of RCF damage resulting from the testing. So far, the study of microstructural change has been limited to the works of Sugino et al., who reported WEAs and DERs during RCF

tests with a radial type rig [6], and Hiraoka et al., who observed microcracks and WEAs with a thrust type test rig [7].

By considering the stress state applying Hertzian elastic contact theory [8], this work examines damage evolution during RCF testing. The formation of WEAs or DERs is studied in combination with subsurface hardness evolution. The crack distributions and orientations are explained by taking 
into account of the residual stress development. A brief description of the stress state based on Hertzian theory is available in Appendix A and B as a supplementary material. The adjoining paper [9] replicates this by employing a laboratory repetitive push testing methodology, demonstrating that it is possible to reproduce subsurface hardening in $100 \mathrm{Cr} 6$ martensite in an accelerated manner.

\section{Materials and methods}

A 100Cr6 steel (0.93-1.05C-1.35-1.60Cr-0.25-0.45Mn-0.15-0.35Si-0.10(max.) Mo, in wt\% [10]) was employed for this study. It was partially austenitised at $860{ }^{\circ} \mathrm{C}$ for 20 minutes, oil-quenched to $60{ }^{\circ} \mathrm{C}$, and kept for 10 minutes; then, it was tempered at $160{ }^{\circ} \mathrm{C}$ for 90 minutes. The resulting microstructure was tempered martensite showing HV0.5 834 10 .

A ball-on-rod RCF test rig supplied by Delta Research Corporation was employed. The specimen morphology was cylidrical with $9.53 \mathrm{~mm}$-diameter and $\sim 78 \mathrm{~mm}$-length. In this tester, the sample was brought into contact with three balls with a $6.35 \mathrm{~mm}$-radius by three springs (Fig. 1a). The spring force $\left(F_{\text {spring }}\right)$ generates the radial force, $F_{\text {rad }}$, inducing the maximum Hertzian pressure $\left(p_{0}\right)$ on the specimen (Fig. 1b). The sample is fixed onto a collet and rotated by a motor. A more detailed explanation of the test rig can be found in [11]. The test conditions for this study are listed in Table 1. The balls with arithmetic roughness of $0.020 \mu \mathrm{m}$, which is lower than that in [11], were used to lower the possibility of surface initiated failure.

In order to investigate the microstructure, the tested samples were sec-

tioned as shown in Fig. 2. The grooves generated during testing were clearly 
seen by the naked eye in the central region. Each groove was cut out separately and both axial and circumferential sections were observed. Especially for the circumferential sections, the sample was firstly cut close to the groove and carefully ground to the deformed region. The unaffected area was cut into a thin plate with a rectangular section. The sectioned parts were coldmounted, mechanically ground with silicon carbide papers, polished with $6 \mu \mathrm{m}, 1 \mu \mathrm{m}$ diamond suspensions, and final-polished with colloidal silica. Then, X-ray diffractometry (XRD) was carried out with a Philips PW1820 diffractometer using $\mathrm{Cu} \mathrm{K} \alpha$ radiation at $40 \mathrm{kV}$ and $40 \mathrm{~mA}$ to determine the amount of retained austenite in the initial structure. The $2 \theta$ range was $35-125^{\circ}$ with a $0.04^{\circ}$-step and 5 s-dwell time per step. The data was analysed via Rietveld refinement with Fullprof version 0.50 software. Then, the microstructures were observed employing optical microscopy (OM) and scanning electron microscopy (SEM) with a Leica DM 2500M microscope and a JEOL 5800LV, respectively, after etching with 2\% nital. For SEM imaging, a $10 \mathrm{keV}$ electron beam was used under a working distance of 5-10 mm; and for energy dispersive spectroscopy (EDS), a $15 \mathrm{keV}$ beam was used with 10 mm-working distance. In addition, the residual cementite in the initial microstructure was quantified by the point counting method from a SEM image covering a $100 \times 120 \mu \mathrm{m}^{2}$-area. The orientation of the microcracks adjacent to the inclusions was identified by measuring the angle between the cracks and the specimen surface. When the crack was inclined towards the overrolling direction ( $x$-axis), the sign was defined to be positive and vice versa as shown in Fig. 3. When multiple cracks were observed around a single inclusion, the angles of all cracks were measured and counted separately. 
The hardness profiles under the surface were obtained by microindentation with a $500 \mathrm{~g}$-load and $15 \mathrm{~s}$-dwell time. With maximum contact pressure, $p_{0}$ in Table 1, the width of the contact area is estimated to be $400-850 \mu \mathrm{m}$ in Appendix A (Fig. A.2a) based on Hertzian elastic contact theory. Three columns of indentations were made alongside the contact area, as shown in Fig. 4. The depth of maximum shear stresses $\left(\tau_{1}, \tau_{x z}\right)$ for two and three dimensional (2D and 3D) contact is $100-340 \mu \mathrm{m}$ (Appendix A, Fig. A.2b), and indicated as well. Note that the responsible shear stress for plastic deformation is ambiguous because the depths showing their maximum overlap [12]; therefore, both depths for the maximum principal shear stress $\left(\tau_{1}\right)$ and

orthogonal shear stress $\left(\tau_{x z}\right)$ are shown. Since the indentation diagonals were always smaller than $50 \mu \mathrm{m}$, the minimum recommended spacing between the indents, $2.5 \times$ (length of the indentation diagonal), is satisfied [13].

\section{Results}

\subsection{Microstructures}

The microstructure prior to RCF testing is shown in Fig. 5. Globular particles ranging hundreds of nanometres are residual cementite from partial austenitisation, occupying $5.1 \pm 0.8 \mathrm{vol} \%$, and the matrix is tempered martensite. The amount of retained austenite was $12.8 \pm 0.2 \mathrm{wt} \%$.

After testing, no indication of decay in the matrix or in residual cementite was observed by OM and SEM. However, a number of microcracks stemming from some inclusions were observed for all test conditions in the circumferential section. The inclusions with microcracks were counted in $100 \mu$ m-depth ranges (e.g. 0-100 $\mu \mathrm{m}, 100-200 \mu \mathrm{m}, 200-300 \mu \mathrm{m}$, etc.) for each $p_{0}$ condition, 
and their frequency variation with depth under the contact surface is shown in Fig. 6. It is seen that the relative maximum of the curves generally shifts to deeper regions with increasing $p_{0}$. This is consistent with the prediction of Hertzian contact theory that the maximum $\tau_{x z}$ or $\tau_{1}$ moves into deeper regions when $p_{0}$ increases (Appendix A, Fig. A.2b). Regarding the crack orientations, they varied from $-50^{\circ}$ to $+60^{\circ}$, with most of them concentrated between $-10^{\circ}$ and $+20^{\circ}$, as shown in Fig. 7. However, the angle distribution does not seem to show a clear correlation with depth, $p_{0}$, or number of cycles $(N)$.

The morphology of the cracks does not depend on the test conditions, and shares some common features. Some representative micrographs of microcracks are shown in Fig. 8a,b. The crack size varied from $1 \mu \mathrm{m}$ up to $\sim 15$ $\mu \mathrm{m}$. Most cracks were in pairs spreading from opposite sides of one inclusion; they were sometimes connected by partly enveloping or penetrating the inclusion. A single inclusion may have multiple cracks with different orientations. Note that the investigations were based on 2D sectioning; therefore, not all cracks around each inclusion could be observed and, sometimes, one single crack was observed with an inclusion. Among all observed microcracks, approximately $10 \%$ were decorated by WEAs regardless of the test conditions; they were usually inclined with respect to the surface more than $10^{\circ}$. It is clearly seen in Fig. 8b that WEAs were always accompanied by microcracks. The inclusions with cracks were of different types as determined by EDS; the compositions of some inclusions are listed in Table 2. It seems that the microcracks could form at all kinds of inclusions. Another interesting feature is that although two inclusion particles were very close to each other, only 
one of them was accompanied by cracks.

Cracks over $100 \mu \mathrm{m}$ in length appeared at higher pressures $\left(p_{0}=4.7,5.2\right.$, $5.6 \mathrm{GPa})$. The cracks lie at a depth of few hundred micrometres and were nearly parallel to the surface as shown in Fig. 8c. Some cracks penetrated prior austenite grain boundaries and bypassed residual cementite particles. Some were observed to lie together, crossing each other. In this case, larger cracks lie horizontally and sometimes form a long intermittent line adjoining various horizontal cracks. However, the short cracks may not be parallel to the surface.

Additional micrographs of cracks can be found in Appendix C (supplementary material), where the accurate location and test condition corresponding to each crack are given.

\subsection{Microindentation hardness}

Hardness depth profiles are given in Fig. 9. The common trend is that the hardness reaches a maximum approximately at $z=100 \mu \mathrm{m}$, and decreases to the unaffected value at $z>350 \mu \mathrm{m}$. According to this, the depth showing the peak hardness corresponds well with that of maximum $\tau_{1}$ for $3 \mathrm{D}$ contact or maximum $\tau_{x z}$ for $2 \mathrm{D}$ contact (Fig. 4). The degree of strengthening depends on $p_{0}$; the maximum hardness reaches up to $\sim 900$ with $p_{0}=5.6 \mathrm{GPa}$. Moreover, the depth range showing strengthening is broadened with increas-

ing $p_{0}$. However, the effect of $N$ does not seem to be significant at least in the tested regime, which suggests that the responsible mechanism for hardness change occurred at $N<10^{7}$ cycles. 


\section{Discussion}

In this study, RCF was observed to be accompanied by two types of changes. Localised damage was manifested by microcracks observed around inclusions, as well as a gradual subsurface hardness increase with depth, which maximum corresponded with the subsurface maximum shear stress location. Although both the possibility of finding an inclusion with microcracks (Fig. 6), and the hardness evolution (Fig. 9) showed similar profiles with the depth, the responsible mechanisms for the occurrence of either is dissimilar.

Considering that the hardness increase occurred before $N=10^{7}$ cycles, and that the residual stress increases the hardness [14], it is conjectured that the responsible mechanisms would be (i) stress induced martensitic transformation of retained austenite, and (ii) dislocation generation and rearrangement. Both phenomena are observed to appear at early stages of deformation $[15,16]$, and since these are caused by plastic deformation, they are consistent with the fact that the location of the maximum shear stress and hardness coincides. Hardness increase was also observed by Sugino et al. [6] at the early stages of testing, being attributed to martensite transformation of retained austenite. Although they also observed hardness decrease accompanying DER formation, such microstructural alteration was not observed in this study.

The formation of microcracks is a form of localised damage occurring adjacent to inclusions. The results suggest that microcracks originate from stress concentration around inclusions, which are known to be the effective stress-raisers [17]. Since WEAs were never observed without microcracks, 
the microcracks may be a prerequisite for WEA formation [6], although this cannot be proven at this stage. Based on this suggestion and considering that WEAs formed on the microcracks inclined more than $10^{\circ}$, it seems that WEAs are formed under special conditions of stress concentration which depend on the microcrack orientation and location. Further studies are necessary to clarify such conditions.

One interesting feature is that the microcrack orientation is most frequent at $-10^{\circ} \leq \theta \leq+20^{\circ}$, in spite of $\theta=45^{\circ}$ being reported to be the most common in thrust type element testing [7], and in full-scale endurance test [18]. If the microcrack morphology depends on the orientation of the $\tau_{1}$ plane, this suggests that the stress state is different in ball-on-rod RCF test rig compared to other configurations. This can be explained in detail with the dependence of residual stresses development on contact geometry [8]. At the first rolling contact, $\tau_{1}$ would be as predicted by Hertzian theory and the $\tau_{1}$ plane for the maximum $\tau_{1}$ would lie at $45^{\circ}$ to the surface. However, on further cycling, residual stresses develop and the $\tau_{1}$ plane orientation $\left(\theta_{\tau_{1}}\right)$ changes. This is shown by an example with the 2D contact case in Appendix $\mathrm{B}$; when the residual stress reaches $\sim 0.077 p_{0}, \theta_{\tau_{1}}$ starts to decrease dramatically from $45^{\circ}$ to $0^{\circ}$, as shown in Appendix B, Fig. B.3. $\theta_{\tau_{1}}$ depends not only on how large the generated residual stress is, but also on which residual stresses can be developed. Since these factors are affected by the contact geometry $[8,19]$, various testing strategies would result in different types of residual stresses, thus producing different damage morphologies. Moreover, the inclusion type would also play a role by introducing a different degree of stress concentration. 
Although the stress states can be different depending on the test methods, the same types of spalls at failure have been observed in other tests [5], which may be the result of propagation of large cracks such as the ones shown in this study (Fig. 8c). Assuming that this large cracks are generated by the coalescence of the microcracks, it can be said that the life of the components would be predicted, at least qualitatively, with the test methods which can produce such microcracks.

\section{Conclusions}

From the microstructural investigation of a 100Cr6 martensitic bearing steel after rolling contact fatigue (RCF) testing with a ball-on-rod tester, it is concluded that:

(1) RCF damage was manifested by a hardness change with depth, and by the formation of microcracks adjacent to inclusions.

(2) The depth of the hardness peak and the maximum possibility of finding the inclusion with microcracks correspond to the maximum subsurface shear stress.

(2) White-etching areas (WEAs) are observed along microcracks inclined more than $10^{\circ}$ with respect to the rolling direction. Dark etching regions were not observed in this study.

(3) It is suggested that the hardness increase is due to the residual stress development at the early stage of the deformation $\left(N<10^{7}\right.$ cycles $)$.

(4) The microcracks formation seems to be assisted by stress concentration around inclusions.

(5) The microcrack morphology depends on different stress states determined 
by the inclusion types and the test methods.

(6) Residual stress development is suggested to play an important role in the morphology of RCF damage, by directly affecting the stress state.

\section{Acknowledgments}

This work was supported by SKF Engineering \& Research Centre and financed by SKF AB. The authors would like to express a sincere gratitude to Prof. A. L. Greer for the provision of laboratory facilities at the University of Cambridge.

\section{Reference}

[1] J. H. Kang, B. Hosseinkhani, P. E. J. Rivera-Díaz-del Castillo, Materials Science and Technology 28 (2012) 44-49.

[2] T. A. Harris, M. N. Kotzalas, Advanced Concepts of Bearing Technology: Rolling Bearing Analysis, Fifth Edition, Rolling Bearing Analysis, Fifth Edition Series, Taylor \& Francis, 2006.

[3] E. V. Zaretsky, R. J. Parker, W. J. Anderson, in: Rolling Contact Fatigue Testing of Bearing Steels, volume 771 of ASTM STP, American Society for Testing and Materials, 1982, pp. 5-45.

[4] J. M. Hampshire, J. V. Nash, G. E. Hollox, in: Rolling Contact Fatigue Testing of Bearing Steels, volume 771 of ASTM STP, Americal Society for Testing and Materials, 1982, pp. 46-66. 
[5] E. N. Bamberger, J. C. Clark, in: Rolling Contact Fatigue Testing of Bearing Steels, volume 771 of ASTM STP, Americal Society for Testing and Materials, 1982, pp. 85-106.

[6] K. Sugino, K. Miyamoto, M. Nagumo, K. Aoki, Transaction of the ISIJ 10 (1970) 98-111.

[7] K. Hiraoka, M. Nagao, T. Isomoto, Journal of ASTM International 3 (2006) $1-7$.

[8] K. L. Johnson, Contact Mechanics, Cambridge University Press, 1987.

[9] J. H. Kang, P. E. J. Rivera-Díaz-del Castillo, Fatigue in martensitic 100Cr6: A new laboratory fatigue testing technique, 2014. Submitted to Materials Science and Engineering A.

[10] ISO, Heat-treated steels, alloy steels and free-cutting steels Part 17: ball and roller bearing steels, Technical Report 683-17:1999, International Organization for Standardization, 1991.

[11] D. Glover, in: Rolling Contact Fatigue Testing of Bearing Steels, volume 771 of ASTM STP, Americal Society for Testing and Materials, 1982, pp. $107-124$.

[12] H. Schlicht, E. Schreiber, O. Zwirlein, in: Effect of Steel Manufacturing Processes on the Quality of Bearing Steels, volume 987 of ASTM STP, ASTM, 1988, pp. 81-101.

[13] ASTM, Standard test method for Knoop and Vickers hardness of materials, Technical Report E384-11, ASTM International, 2011. 
[14] J. Frankel, A. Abbate, , W. Scholz, Experimental Mechanics 33 (1993) 164-168.

[15] F. J. Humphreys, M. Hatherly, Recrystallization and Related Annealing Phenomena, Elsevier Science, 2004.

[16] A. P. Voskamp, Microstructural changes during rolling contact fatigue, Ph.D. thesis, TU Delft, 1996.

[17] Y. Murakami, Metal fatigue: effects of small defects and nonmetallic inclusions, Elsevier Science, 2002.

[18] P. C. Becker, Metals Technology 8 (1981) 234-243.

[19] J. E. Merwin, K. L. Johnson, Proceedings of the Institution of Mechanical Engineers 177 (1963) 676-690. 

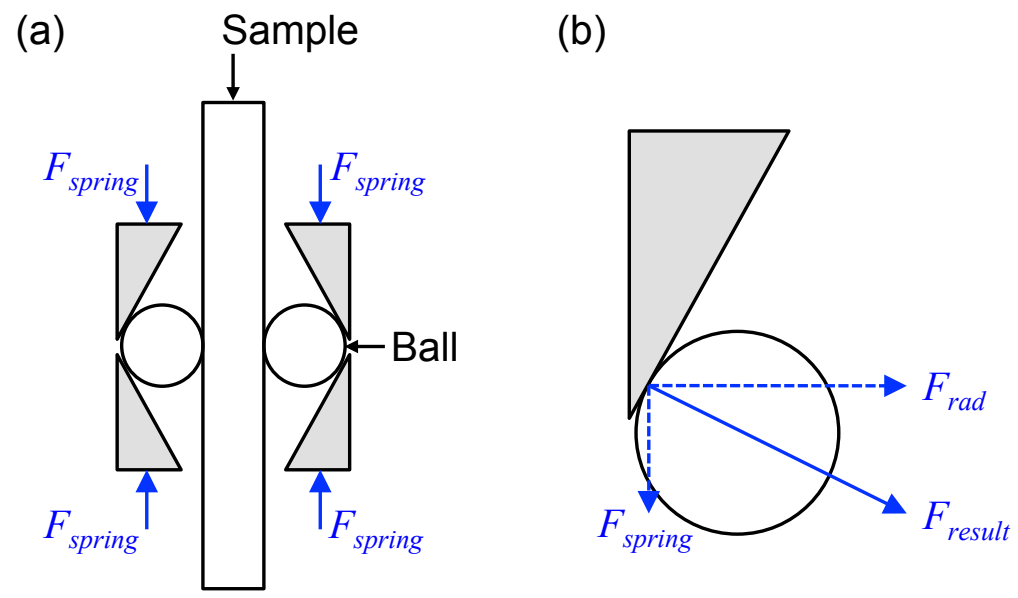

Figure 1: Schematic diagrams showing the loading condition in the ball-on-rod testing. (a) A rod sample in contact with balls by the spring force, $F_{\text {spring }}$. (b) Forces generated by $F_{\text {spring }}$.

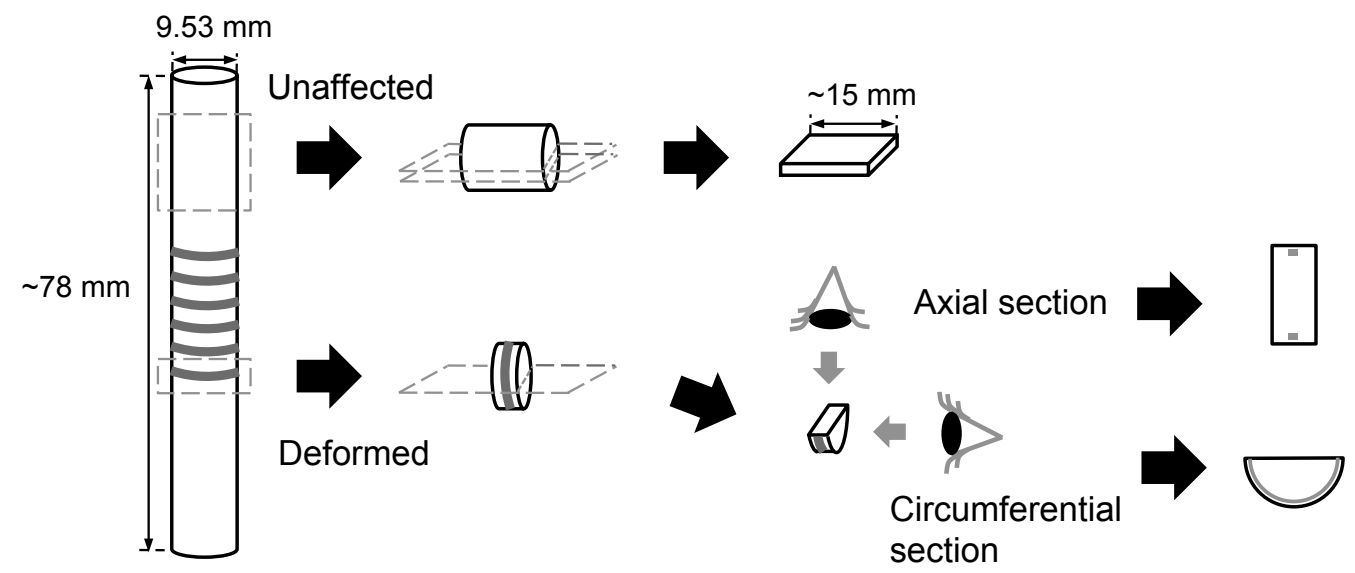

Figure 2: Schematic diagram showing the sample preparation procedure. The possible affected regions are shown in grey. 


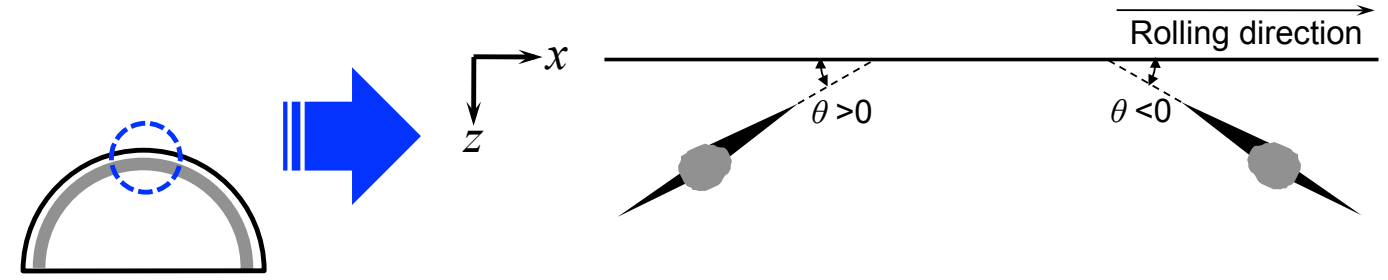

Figure 3: The sign determination for the microcrack orientation, $\theta$, which is observed in the circumferential section.

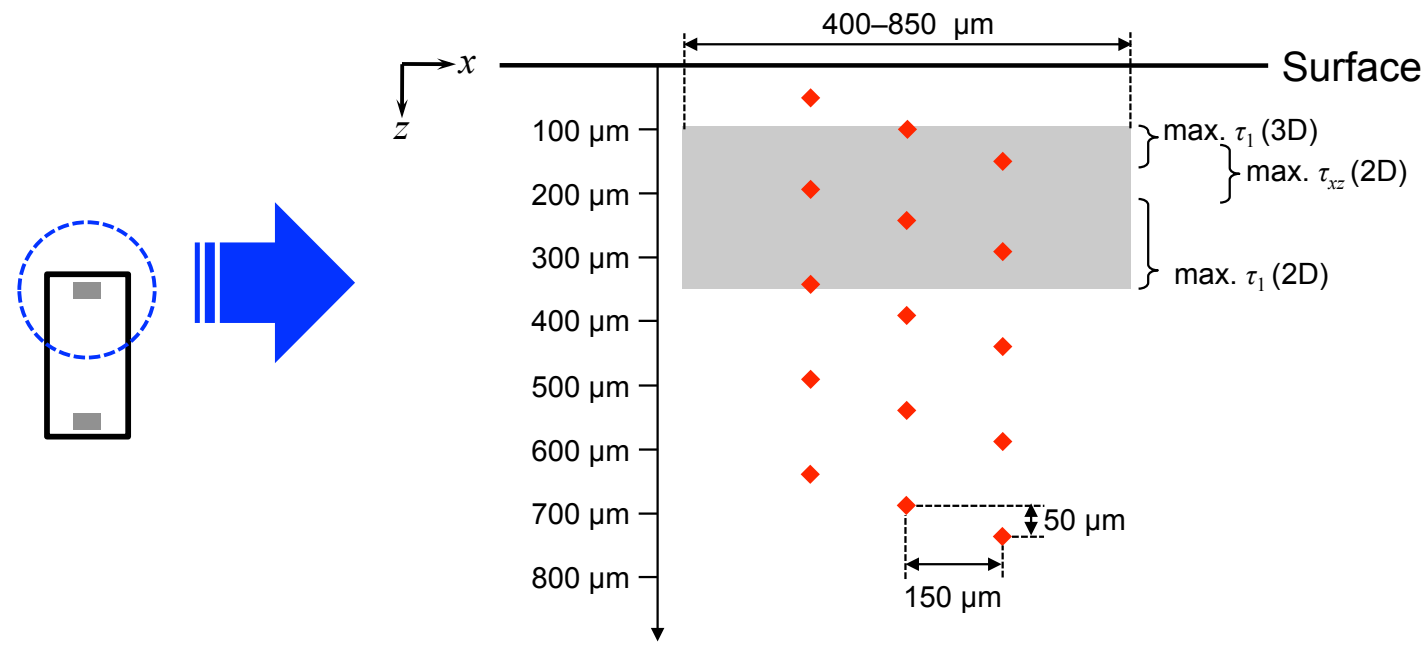

Figure 4: Microindentations made to obtain the hardness profile under the specimen surface in the axial section. The regions with maximum shear stresses are calculated and shown in grey. 


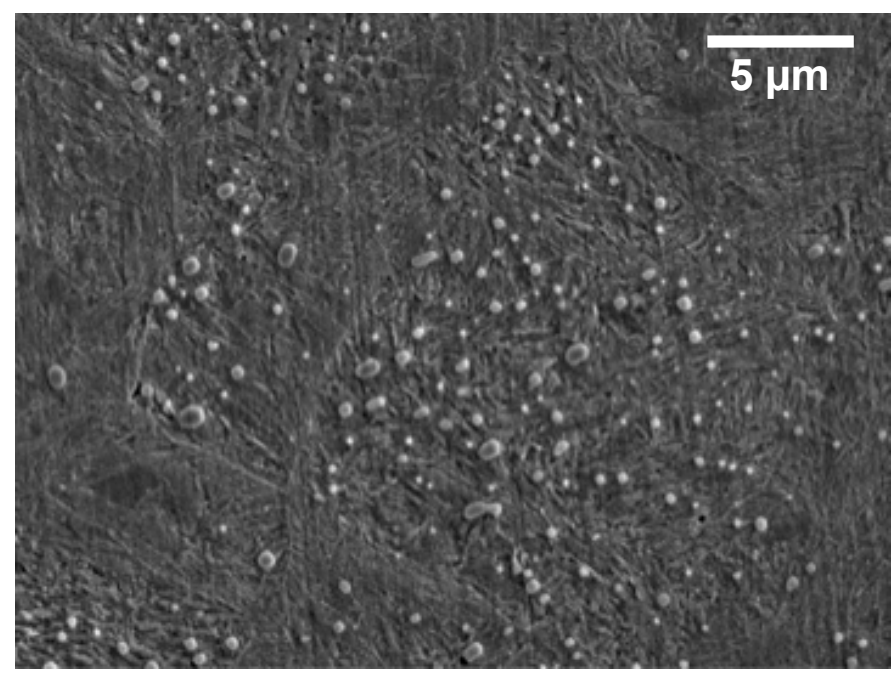

Figure 5: Secondary electron micrograph of the microstructure before testing.

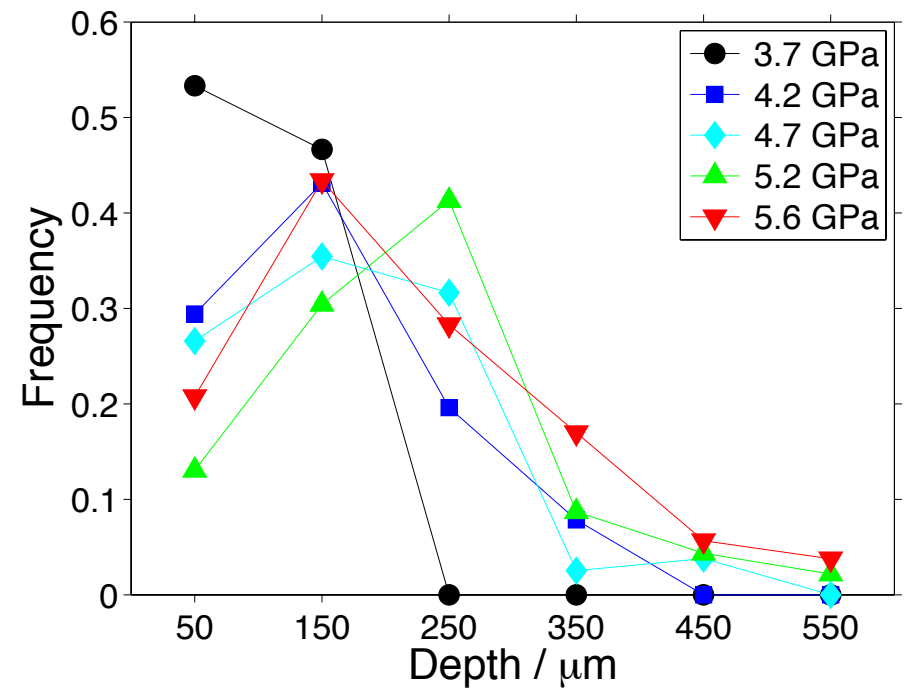

Figure 6: Varation in the frequency of microcracks with depth with different values of $p_{0}$. 


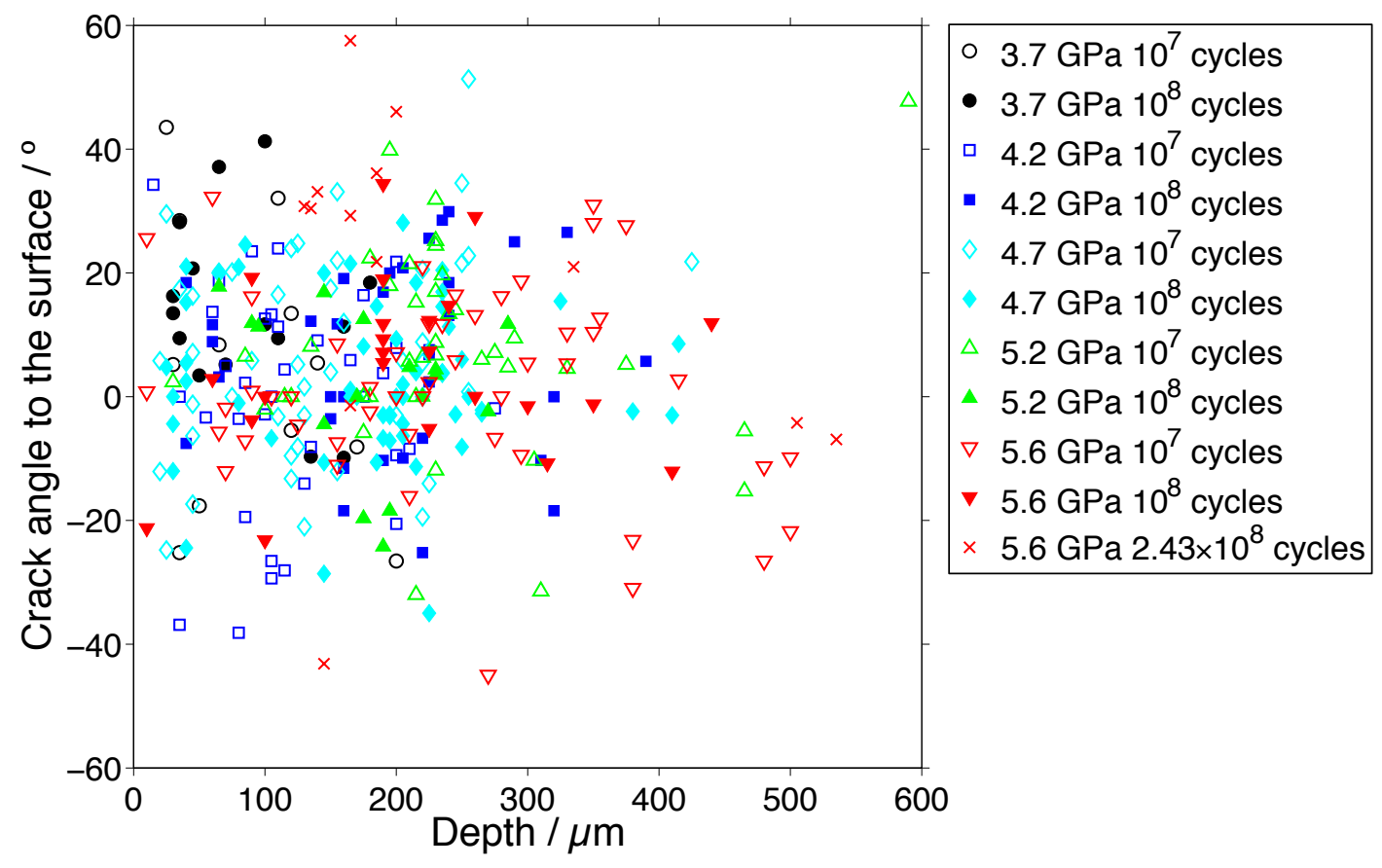

Figure 7: Microcrack angle variation with depth for different test rig conditions. 
(a)

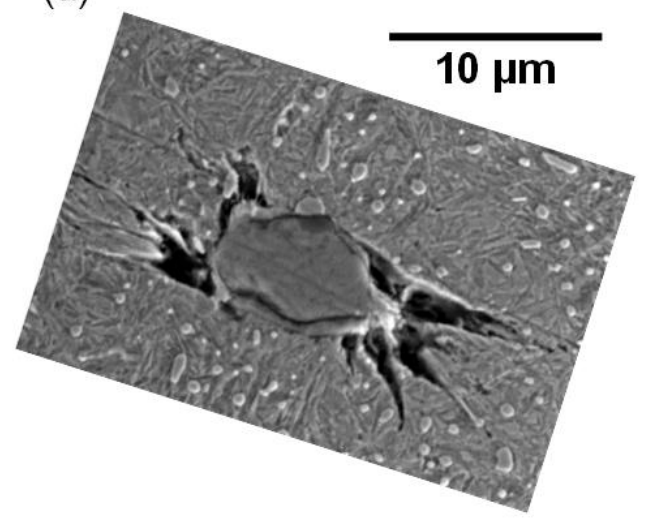

(b)

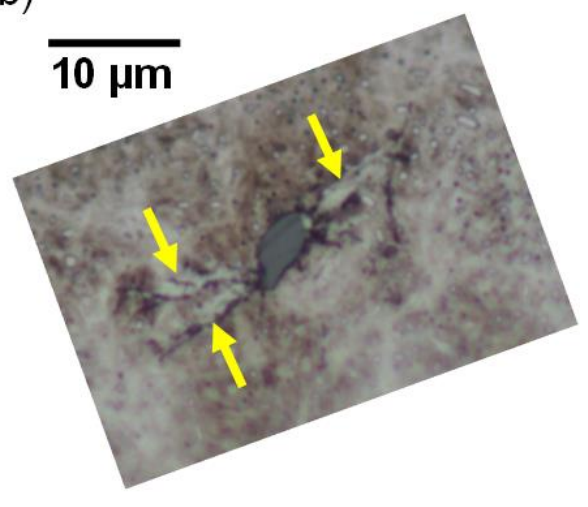

(c)

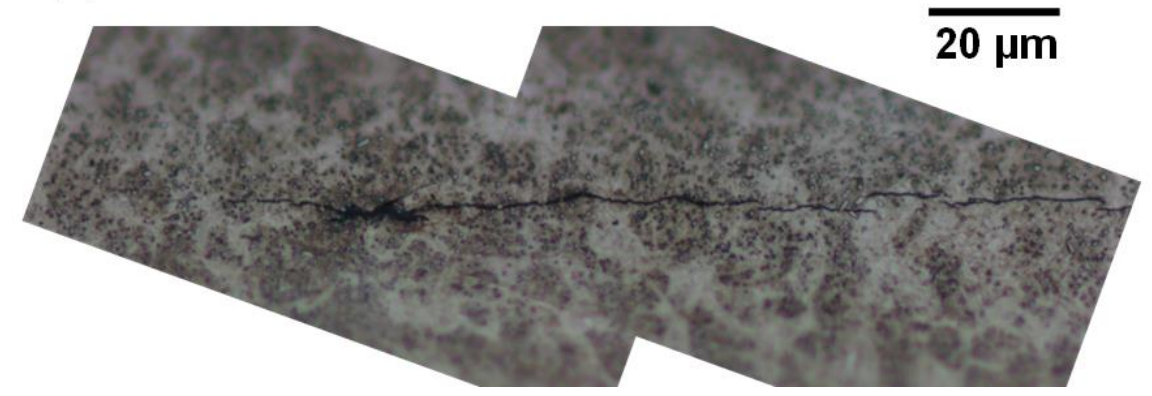

Figure 8: (a) Scanning electron micrograph of microcracks around an inclusion. (b) Optical micrograph of white-etching areas (marked with yellow arrows) formed near to microcracks. (c) Optical micrograph of larger cracks. The images are tilted so that the specimen surface lies along the horizontal direction. 
(a)

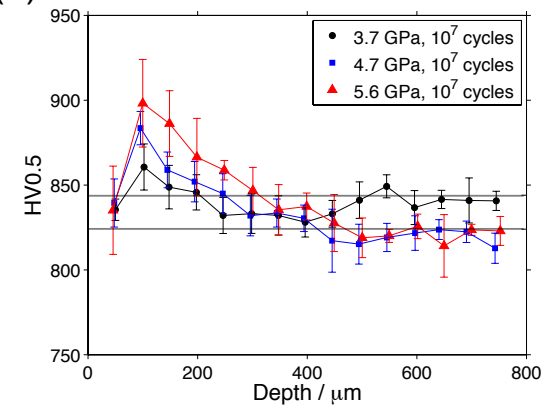

(b)

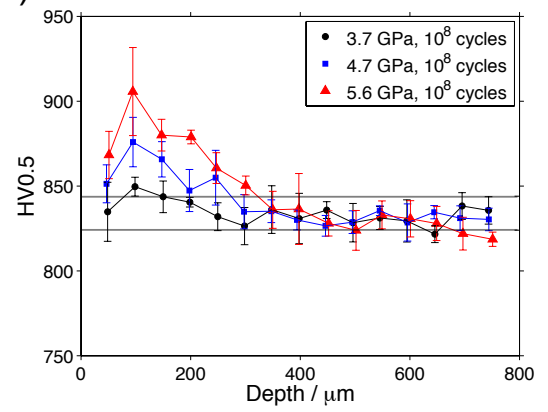

Figure 9: Hardness profiles for (a) $N=10^{7}$ cycles and (b) $N=10^{8}$ cycles with different contact pressures. The horizontal lines show the hardness ranges of the initial microstructure. 
Table 1: Conditions for the ball-on-rod rolling contact fatigue test in the study. $\left(p_{0}\right.$ : Maximum Hertzian pressure, $N$ : number of cycles)

\begin{tabular}{cc}
\hline Parameter & Value \\
\hline$p_{0}$ & $3.7,4.2,4.7,5.2,5.6 \mathrm{GPa}$ \\
$N$ & $10^{7}, 10^{8}$ cycles, \\
& $2.43 \times 10^{8}$ cycles only for $p_{0}=5.6 \mathrm{GPa}$ \\
Speed & 3600 revolutions per minute $(=144.3 \mathrm{~Hz})$ \\
Lubrication & BP Turbo Oil 2380 \\
Lubrication feed rate & 10 drops per minute \\
\hline
\end{tabular}

Table 2: Composition of some inclusions and their expected nature. The morphology of each inclusion can be found in the supplementary materials.

\begin{tabular}{ccccccc}
\hline & Inclusion 1 & Inclusion 2 & Inclusion 3 & Inclusion 4 & Inclusion 5 & Inclusion 6 \\
\hline $\mathrm{Fe} / \mathrm{wt} \%$ & $2.7 \pm 0.3$ & $26.3 \pm 0.4$ & $7.7 \pm 0.3$ & $51.2 \pm 0.4$ & $15.0 \pm 0.4$ & $2.5 \pm 0.3$ \\
$\mathrm{Cr} / \mathrm{wt} \%$ & $1.1 \pm 0.2$ & $0.9 \pm 0.2$ & - & $0.9 \pm 0.1$ & $2.2 \pm 0.2$ & $1.9 \pm 0.2$ \\
$\mathrm{Mn} / \mathrm{wt} \%$ & $51.5 \pm 0.3$ & $34.9 \pm 0.4$ & - & - & $37.7 \pm 0.4$ & $56.4 \pm 0.3$ \\
$\mathrm{~S} / \mathrm{wt} \%$ & $40.2 \pm 0.3$ & $34.5 \pm 0.3$ & - & - & $34.0 \pm 0.3$ & $38.8 \pm 0.3$ \\
$\mathrm{O} / \mathrm{wt} \%$ & - & $2.9 \pm 0.5$ & $44.7 \pm 0.3$ & $7.9 \pm 0.2$ & - & - \\
$\mathrm{Al} / \mathrm{wt} \%$ & - & - & $35.3 \pm 0.3$ & $19.2 \pm 0.2$ & - & - \\
$\mathrm{Mg} / \mathrm{wt} \%$ & $2.8 \pm 0.1$ & $0.5 \pm 0.1$ & $12.4 \pm 0.2$ & $20.8 \pm 0.4$ & - & $0.5 \pm 0.1$ \\
$\mathrm{Ca} / \mathrm{wt} \%$ & $1.6 \pm 0.1$ & - & - & - & - & \\
\hline Type & $\mathrm{MnS}$ & Oxysulfide & Spinel & Spinel & $\mathrm{MnS}$ & $\mathrm{MnS}$ \\
\hline
\end{tabular}

